\title{
100-YEAR OLD HAEMATOLOGICA IMAGES: DI GUGLIELMO DISEASE OR PURE ERYTHROID LEUKEMIA
}

\author{
Carlo L. Balduini
}

Ferrata-Storti Foundation, Pavia, Italy

E-mail: CARLO L.BALDUINI, - carlo.balduini@unipv.it

doi:10.3324/haematol.2020.248039

I 1917, Giovanni Di Guglielmo, at that time a young collaborator of Adolfo Ferrata at the University of Naples, Italy, described in Folia Medica a patient with an hematological disorder characterized by an increased number of granulocytes, erythrocytes and platelets and the presence of precursors of all these elements in circulation. ${ }^{1}$ He classified this patient as affected by eritroleucopiastrinemia (erythro-leuko-thrombocythemia), a form that we would nowadays include in the context of myeloproliferative diseases. Until the description of this patient only leukemias characterized by proliferation of myeloid or lymphoid series were known, but the observation of this patient gave Di Guglielmo the idea that primitive bone marrow elements can abnormally proliferate not only along the myeloid line, but also along the erythropoietic and thrombopoietic lines. In particular, he hyphothesized that generalized erythroblastic proliferation throughout all organs of the body could be expected. Ten years later, he described in Haematologica two cases of what he had claimed would ultimately be found: acute erythremic myelosis. ${ }^{2}$

The image on the cover of this issue of Haematologica is one of the fine, hand-drawn color plates illustrating this article published in 1928 (Figure 1). Immature and atypical erythroid precursors were the dominant elements in peripheral blood and bone marrow of these severely anemic, neutropenic and thrombocytopenic patients. Abnormal erythroblasts were found also in the liver and spleen. The course of the disease was hyperacute and both patients died within a few weeks.

Old concepts are cast in cement and the idea of a leukemia of the erythroid line was new and unorthodox at that time and, therefore, Di Guglielmo was unable to convince anyone for a long time, his mentor Ferrata included, ${ }^{3}$ that the proliferation of erythroblasts can not only have a reactive origin, but that it can also represent a genuine leukemia in rare cases. However, other similar cases were reported by Di Guglielmo himself and by other authors in subsequent decades and, eventually, most people accepted the idea that leukemia of the erythroid series really exists. In 1940, Dameshek proposed for this disorder the name of Di Guglielmo disease. ${ }^{4}$ Then, the French-American-British (FAB) cooperative group, in their first proposal in 1976, included it within the Acute Myeloid Leukemia classification system as erythroleukemia, M6. ${ }^{5}$ The 2016 revision to the World Health Organization classification of myeloid neoplasms and acute leukemia gave this disorder the name of pure erythroid leukemia, ${ }^{6}$ a denomination that would have had full approval by Di Guglielmo.

In conclusion, the first patients with pure erythroid leukemia were described by Di Guglielmo in Haematologica in $1928,7,8$

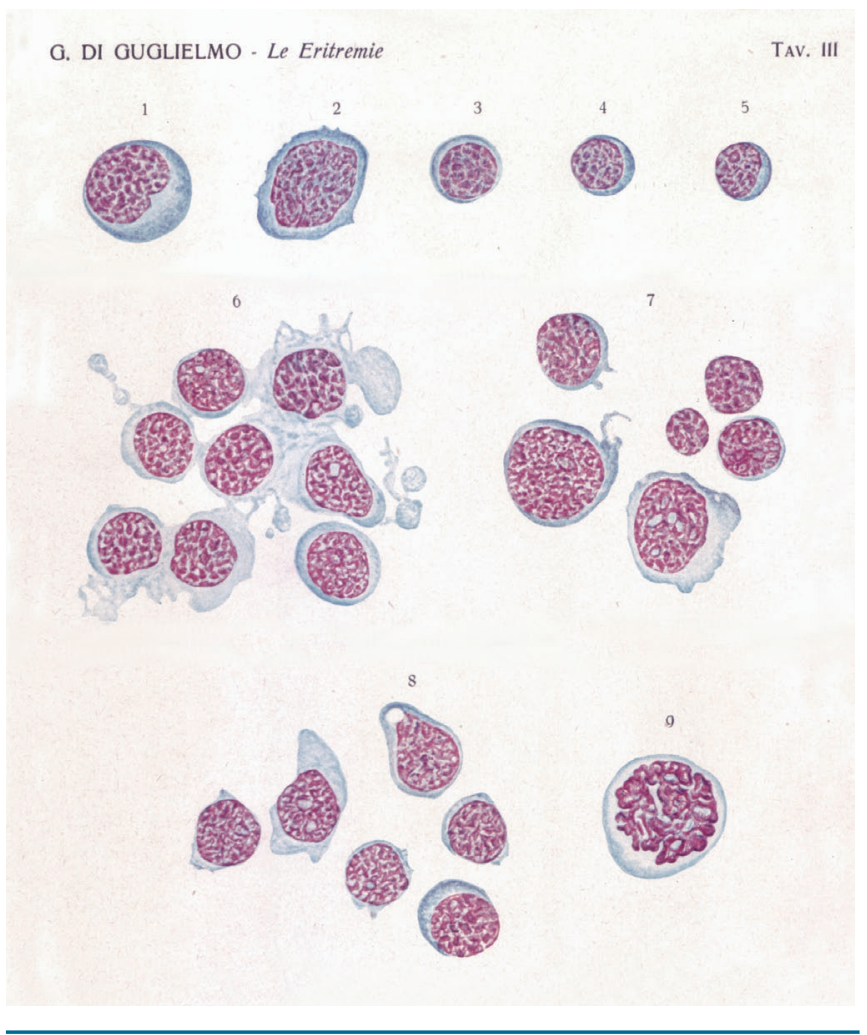

Figure 1. One of the figures of the Haematologica article describing for the first time acute erythremic myelosis, presently known as pure erythroid leukemia. According to the author's caption: "Images 1-5, erythroblastic elements in peripheral blood; Images 6- 8, groups of erythroblasts in the spleen (smear preparations) and Image 9, erythroblastic karyokinesis (spleen smear preparation)".

\section{References}

1. Di Guglielmo G. [Un caso di eritroleucemia]. Folia Med. 1917;13:386.

2. Di Guglielmo G. [Le eritremie]. Haematologica. 1928;9:301-347.

3. Wintrobe MM. The role of Giovanni Di Guglielmo in the history of hematology, in: Commemorazione di Giovanni di Guglielmo nel centenario della nascita. (E. Ascari, C.L. Balduini, M. Cazzola, M. Gobbi, A. Riccardi, G. Ucci EDS) Edizioni Medico Scientifiche Pavesi, Pavia (1986), pp 8-17.

4. Dameshek W. The Di Gugliemo syndrome. Blood. 1940;13:192

5. Bennett JM, Catovsky D, Daniel MT, et al. Proposals for the classification of the acute leukaemias. French-American-British (FAB) co-operative group. Br J Haematol. 1976;33(4):451-458.

6. Arber DA, Orazi A, Hasserjian R, et al. The 2016 revision to the World Health Organization classification of myeloid neoplasms and acute leukemia. Blood. 2016;127(20):2391-2405.

7. Boddu P, Benton CB, Wang W, Borthakur G, Khoury JD, Pemmaraju N. Erythroleukemia-historical perspectives and recent advances in diagnosis and management. Blood Rev. 2018;32(2):96-105.

8. Mazzarello P. One hundred years of Haematologica. Haematologica. 2020;105(1):12-21. 